
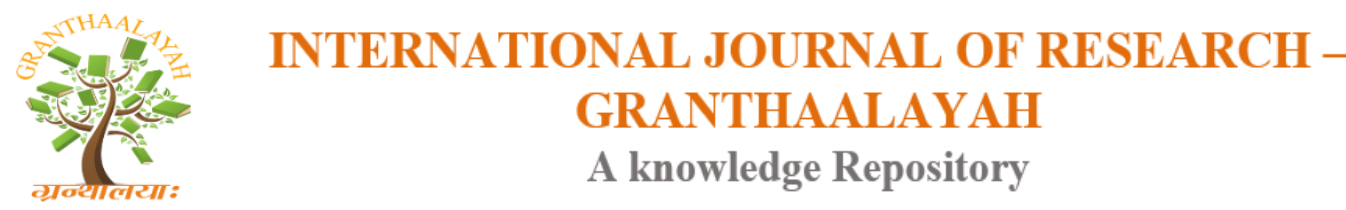

Management

\title{
OPTIMIZATION OF RESOURCES WITH THE AID OF LINEAR PROGRAMMING MODEL IN STEVE SHOE PRODUCTION CENTRE, ENUGU, NIGERIA
}

\author{
Osagie, Godwin Nosakhare Ph.D *1, Icheme, Monday Ojochide ${ }^{2}$ \\ ${ }^{* 1}$ Department of Business Administration, Ambrose Alli University, Ekpoma, Nigeria \\ ${ }^{2}$ Postgraduate Student, Department of Management, University of Nigeria Enugu Campus, \\ Enugu, Nigeria
}

\begin{abstract}
This paper studied the optimization of resources with the aid of linear' programming model in Steve Shoe Production Centre (SSPC), Enugu. The Linear programming model is a complex mathematical tool used for solving managerial decision problems. From the researcher's observation, Steve Shoe Production Centre depended completely on trial and error method of decision making which often yielded suboptimal results. This gap brought about the need to amongst others demonstrate how the linear programming model developed in this study can assist SSPC Enugu to optimize its resources for effective output decisions. Review of related literature was performed. The findings show that the linear programming model developed by the researcher is workable for optimal results in Steve Shoe Production Centre, Enugu.
\end{abstract}

Keywords: Linear Programming Model; Resource Optimization.

Cite This Article: Osagie, Godwin Nosakhare, and Icheme, Monday Ojochide. (2018). "OPTIMIZATION OF RESOURCES WITH THE AID OF LINEAR PROGRAMMING MODEL IN STEVE SHOE PRODUCTION CENTRE, ENUGU, NIGERIA.” International Journal of Research - Granthaalayah, 6(9), 123-136. https://doi.org/10.5281/zenodo.1436782.

\section{Introduction}

Organizations are set up to achieve goals and objectives. In trying to achieve the goals and objectives, decisions are to be made and resources have to be deployed. One of the techniques that can assist managers of business organizations in this regard is Operations Research. It assists managers in making effective decisions in order to achieve efficiency, increase productivity and overall corporate performance, According to Akingbade, Luck and Ratal (1991), it is a problemsolving science-based activity using analysis and modeling as a basis for aiding decision-makers in organizations to improve the performance of the operations under their control. It is concerned with analyzing complex problems and assisting decision-makers work out the best means of achieving objectives. It can be said to have been in existence since the beginning of mankind (Agbadudu, 2006). However, the concept emerged in 1940 during the Second World War, when a 
team of the scientist was called upon by the military management in England to develop ways to make the most effective use of limited military resources (Anderson, Sweeney, \& Williams, 1997; Ta'ha, 2002). Their mission was to formulate specific proposals and plans for aiding the military commands to arrive at decisions on optimal utilization of scarce military resources and also to implement the decisions effectively.

The name "Operations Research" originated because the team was handling research on (military) operations. The United States military management took a leaf from the British military management and started the use of Operations Research. Due to the successful utilization of Operations Research by military management in Britain and United States, managers of business organizations became interested in using the techniques to solve organizational problems. Linear programming (LP) can be defined as a mathematical technique for determining the best allocation of a firm's limited resources to achieve the optimum goal. It is also a mathematical technique used in Operation Research (OR) or Management Sciences to solve specific types of problems such as allocation, transportation and assignment problems that permits a choice or choices between alternative courses of action (Yahya, 2004).

Linear programming (LP) is a term that covers a whole range of mathematical techniques that is aimed at optimizing performance in terms of combinations of resources (Lucey, 2002). Linear programming being the most prominent Operational Research Technique (ORT), it is designed for models with linear objective and constraint functions. A linear programming model can be designed and solved to determine the best course of action as in a product mix subject to the available constraints. Generally, the objective function may be of maximization of profit or minimization of costs or labor hours. Moreover, the model also consists of certain structural constraints which are set to conditions that the optimal solution should justify. Examples of the structural constraints include the raw material constraints, production time constraint, and skilled labor constraints to mention a few.

An optimum solution is a solution that fulfills both the constraints of the problem and the set objective to be met. The term "linear", as stated by Akingbade (2006), implies proportionality, which means that the elements in a situation are so connected that they appear as a straight line when graphed. While the "programming" indicates the solution method which can be carried out by an iterative process in which a researcher advances from one solution to better solution until a final solution is reached which cannot be improved upon. This final solution is termed the optimal solution to the LP problem.

Linear Programming was developed as a mathematical pattern during World War II to plan expenditures and returns in order to reduce costs to the army and increase losses to the enemy. The method was kept secret until 1947. After the war, many industries began using it. The founders of linear programming are George Dantzig who published the Simplex method in 1947, John von Neumann who developed the theory of duality, and Leonid Kantorovich - the Russian mathematician who applied similar techniques before Dantzig and won the Noble Prize in 1957. Leonid Kantorovich showed, for the first time, in 1979 that the linear-programming problem was solvable in polynomial time, but a larger theoretical and practical breakthrough in the field came in 1984 when Narendra Karmarkar introduced a new interior-point method for solving linear programming problems (Hilier \& Liberman, 2003). 
When linear programming problem is expressed, the management objective is set, and the capability of the linear programming technique for the given problem is ensured, the next step in a real problem-solving situation is to express the problem in a mathematical model. (Guilani-nia, 2005) The elements of a linear programming model are decision variables, objective function, and model constraints. The objective function and constraints of a linear programming model are the decision variables and parameters respectively. The decision variables include mathematical symbols which represent the level of activity of any organization. The objective function is a mathematical linear relationship which expresses the objective of the organization in terms of decision variables. The objective function is always set as maximizing or minimizing. The model constraints also express the linear relation among the decision variables.

The constraints are imposed on the organization by the operational environment and are often due to limited resources or the organization's internal policies (Azar, 1999) When one designs the real decision constraint model, he/she may begin with a simple model which covers a part of the problem. Later on, more real constraints can be added during the next steps. Those with the impression that the whole model could be designed in one step would encounter a very complicated difficult task (Orlin, 2007). The linear programming techniques can be used only when they embody the required assumptions: proportionality, additively, divisibility, and certainty (Mehregan, 1993).

Aiden (2009) is of the view that Nigerian government, in believing that a dynamic and growing small manufacturing sub-sector can contribute significantly to the implementation of wide range development initiatives, has thus enunciated various policies to encourage their proliferation and make them veritable engines of growth and development.

He stated further that the basic activity of the Nigerian government policy measures is to improve the financing and other supportive services of small-scale business by expanding and improving access to credit and infrastructural facilities.

In view of the above opportunities created by the Nigerian government for small business owners, there is therefore, the need for Steve Shoe Production Centre which falls into this category to enhance its operational efficiency and effectiveness in order to make the best use of its resources in the midst of these environmental opportunity by applying one of the models in operations research, known as linear programming model. Every business enterprise strives to profitably exist while ensuring growth and expansion of its business endeavors. In its bid to achieve the above objectives it becomes expedient that critical decisions be made as regards allocation of its scarce resources effectively and also efficiently. These decisions include but are not limited to, competitive price, identification of target market, product standard, level of technology involvement.

In an attempt to minimize cost incurred while maximizing profit earned. Such resource allocation decisions can be facilitated and enhanced through the use of an operations research technique termed linear programming. Linear programming is an optimization instrument, which allows the rationalization of many managerial and/or technological decisions. Based on information available to the researchers, Steve Shoe Production Centre Enugu is engaged in the production of two types of the shoe; small fitting male shoe and small fitting female shoe. In order to produce these pairs 
of shoes, the production center requires different materials in different combinations and uses manual labor intensively in the production process.

The researchers, through observation, noted that decision making regarding the quantity of shoes to be produced by Steve Shoe Production Centre, Enugu was based on trial and error method which often yielded sub-optimal results. This gap has necessitated the need to practically demonstrate the workability of linear programming model in Steve Shoe Production Centre, Enugu to enable the owner to improve his decision making capability. Therefore, the researchers intend to:

1) find out why Steve Shoe Production Centre Enugu, do not use linear programming model in determining their product mix.

2) practically develop a linear programming working model for the production process of Steve Shoe Production Centre, Enugu.

3) demonstrate how the developed linear programming working model can assist Steve Shoe Production Centre, Enugu to optimize its resources for effective output decision.

\section{Review of Related Literature}

Izaz et al (2011) provide an evidence of application of linear programming model in optimal production planning for ICI Pakistan using linear programming. The techniques of linear programming were used to maximize the profit generated from the production patterns of the ICI Pakistan. Four different products manufactured at the company were taken into consideration. The researchers obtained profit and loss data from keenly prepared annual book relevant to the study. The simplex method was used to get the best possible consumption of resources (cost) of the problem for ICI Pakistan. As a matter of nature, the researchers identified some bottlenecks in the study such as the demand for one product being greater than the other. The research considered such bottlenecks in the formulation and modeling of the linear programming problem, the analysis predicted that the production of soda Ash would contribute more than other products to the objective function.

The research revealed that among the other products, soda ash is more profitable to the company and the company should give more attention to its production to maximize its profit. The researcher concluded that the research is significant in the sense that it would assist the top management of the company in making corrective decisions in time using the methods of linear programming. Murugan and Manivel (2009) tried to demonstrate the use of linear programming technique by using linear interactive optimizer (UNDO) software to maximize the profit of Khadi and Village Industries Commission' (KVIC) affiliated to Sarvodaya Sangham, run by a non-governmental organization (NGO). Sarvodaya Sangham engages in the production of three textile products, namely; cotton Khadi/ Khadi ready-made and silk Khadi. Account records indicate that total profit earned by Sarvodaya and Sangham was INR.22.31 million for the year. To produce each unit of the products requires the unit of raw materials cost of INR.32.74 million for cotton Khadi, INR.24.64 million for Khadi ready-made and INR.36.9 million for silk khadi. The unit labor cost of INR.7.36 million, INR.0.68 million and INR.7.58 million for cotton Khadi, Khadi ready-made, and silk Khadi respectively is required while the unit overhead cost of INR.5.79 million, INR.Q.49 million and INR.6.78 million for cotton Khadi, Khadi ready-made, and silk Khadi respectively is incurred. 
The input availability of INR.94.28million, INR.15.62 million and INR.13.06 million for raw material, labor hour time and labor overhead time are used bearing in mind that each product will make a contribution of INR.9.23, INR.0.23 and INR.12.85 in million for cotton Khadi, Khadi ready-made, and silk Khadi respectively. The application of linear, programming suggests that the existing production volume would help to maximize the profit of Sanghan products to the tune of INR.24.752 million, noting that producing silk Khadi alone is economically profitable, the profit is INR.2.442 million higher than that of the present profit of INR.22,31million.

Adeyemo and Otiero (2009) also tried to demonstrate that the linear programming model can be extended beyond the realms of Management Sciences and organizational decision departments to other areas such as Physical and Environmental Sciences. They used the application of Differential Evolution (DE) and Linear Programming (LP) to maximize total income (in South African Rand ZAR) of 2500 ha planting area where 16 crops are planted and constrained by water availability (using only $10 \mathrm{~mm} 3$ of irrigation water). It is found that a total income of ZAR 46,060,200 can be derived using linear programming. Ten strategies of DE are tested with this problem varying the population size (NP), crossover constant $(\mathrm{CR})$ and weighing factor $(\mathrm{F})$. It is found that strategy 1 , DE/and-1-bin, with values of NP, CR, and F of $160,0.95$ and 0.5 respectively obtains the best solution most efficiently.

Kdreern and Aderoba (2008) tried to show the effectiveness of adopting the linear programming model in maintenance and manpower planning using data from a cocoa processing industry in Akure, Ondo State of Nigeria. The result shows that only four maintenance crew out of the 19 employees are needed in that section to effectively carry out maintenance jobs in the industry. But in their own contributions, Nedim et al (2002) tried to demonstrate that risk analysis is necessary in order to maximize resources allocation efficiency and minimize the effects of risk environment. They used data from a sample of a company's products taking risk into account as the objective function. The result suggests that producing 5 units of XI generates $36 \%$ loss possibility. If decision makers aim risk not to exceed certain limits, then, variances should be used as constraints. The model suggests that producing 3 units of XI will decrease the objective function from $\$ 432$ to $\$ 287$.

In another research, Susilawati et al (2002) extended the application of linear programming to dormitory development at Petra Christian University to calculate the number of rooms and area of each 'facility possible considering the limited space of 4,994.83 square meters and a maximum cash flow of Rp 392,952.00 which is discounted by $17 \%$ per annum for seven years. They were able to calculate the number and area of facilities such as bathrooms, dining "rooms, common rooms, cafeterias, bookshops, mini- markets, phone booths, sports facilities and parking spaces using special computer software which can solve mixed integer and LP model called SOLVER. The result suggests that all supporting facilities except garden need to be supplied. But in another study, Andre et al (2003) used linear programming to predict nutrients that are potentially low in a child's diet during the complementary feeding period such that the information gathered can be used to direct nutrition intervention programme initiatives because it suggests that foods rich in (foods fortified with) these limiting or problem nutrients should be introduced into local diets.

Several other empirical studies have shown the applicability of linear programming technique to diverse optimization problems. For instance, Koji and Gunner (2002) reveal the power of linear 
programming in image reconstruction by identifying and updating noisy pixels and applying the v-trick to directly specify the fraction of pixels to be reconstructed. But Dhanalakshm et al (2009) used linear programming in parts of speech tagging of Tamil language in India by projecting an SVM methodology based on linear programming for implementing automatic Farm! POS tagger. In the study, "Quantitative Analysis of mineral mixtures using linear programming", Gerard (1986) demonstrated the determination of a multiphase system by applying X-ray Powder diffraction (XRO) and optimal point-counting methods as the means of obtaining quantitative information on the phase composition of a mixture. Cui et al (2006) also developed an efficient linear programming detector (LPD) for multiple-input-multiple-output (MIMO) systems by employing multiple antennas at both the transmitter and the receiver of a high data-rate MIMO communication system to achieve remarkable high special efficiencies in rich scattering environments.

\section{Theoretical Review}

There are diverse opinions on the applicability of the linear programming technique to different management decision-making processes. These opinions developed over a long period of time following continuous improvement on the application of the technique in solving practical business problems. Most literature in economic development supports the view that linear programming is a practical too: of analysis in allocating scarce resources to their optimal use and is of vital importance to the economies of underdeveloped countries. Tracing the history of linear programming method, it is a mathematical device developed by the mathematician, George Dantzig, in 1947 for planning the diversified activities of the U.S. Air Force connected with the problem of supplies to the Force. Afterwards, Dantzig suggested this approach for solving business and industrial problems. He also developed a powerful mathematical tool known as "simplex method" to solve linear programming problems (Dantzig, 1993).

In an allocation problem, when there are 3 number of activities to be performed, alternative ways of doing them, and limited resources or facilities for performing each activity in the most effective way, the management is faced with the problem of how best to combine these activities and resources in an optimal manner so that the overall efficiency is maximized. According to Charles, Cooper, and Henderson (1963), this is -known as an optimization problem, and can be Approached using mathematical programming, They further refer to linear programming as a uni-objective constrained optimization technique. This is because, according to them, it seeks a single objective of either minimizing or maximizing unknown variables in a model. In line with this, Gupta and Hira (2009) argue that linear programming deals with the linear optimization of a function of variables known as objective function subject to a set of linear equations and /or inequalities known as constraints. The objective function may be profit, cost, production capacity or any other measure of effectiveness which is to be obtained in the best possible or optimal manner. The constraints may be imposed by different resources such as market demand, production process and equipment storage capacity, raw material available, and so on. They further posit that programming implies planning and by linearity is meant a mathematical expression in which the expressions among the variables are linear.

Dwivedi (2008) posits that linear programming is of great use in making a business decision because it helps in measuring complex economic relations and thereby, provides an optimum 
solution to the problem of resource allocation. According to him, linear programming technique thus bridges the gap between abstract economic theories and managerial decision-making. Furthermore, he stressed that any linear programming equation should have three specifications, namely: objective function specification, constraint equation specification, and non-negativity requirement. Corroborating this view, several authors (Koutsoyiannis, 1979; Dowling, 1992; Henderson \& Quandt, 2003; Dwivedi, 2008) have given the general specification of the linear programming model. Sarggeaunt (1965) groups, what he calls, the principal types of application of linear programming models under three headings, namely; blending and mix determination problems, planning and scheduling problems and distribution cost problems. He also notes other types of applications: for instance to plant location decisions, to personnel allocation problems, and to the analysis of a multi-plant production system to determine whether or not certain plants should $\mathrm{b} \$$ shut down as a result of high cost of production.

Emory and Niland (1968) have listed similar types of problems to which linear programming is applied. They include the blending of gasoline stocks, the formulations of various chemical products, the mixing of fertilizer, the manufacture of cement and the charging of electric furnaces. On the other hand, Hillier and Lieberman (2001) assert that although allocating resources to activities is the most common type of application, linear programming has numerous other important applications as well. In fact, any problem whose mathematical model fits the very general format for the linear programming model is a linear programming problem.

Turban and Meredith (1991) agreeing with Dwivedi (2008), states that linear programming is one of the best-known tools for management science. Management science methods are composed of three components; the decision (uncontrolled) variables, the environment (uncontrolled) parameters and results (dependent) variables. The linear programming model, according to them, is composed of the same components but they assume different names; the decision variables which we seek to determine, the objective function which we aim to optimize and the constraints we need to satisfy. But Koutsoyiannis (1979) insists that linear programming can be considered as providing an operation method for dealing with an economic relationship which involves discontinuities. She, however, maintains that neither economic theory nor linear programming says anything about the implementation of the optimal plan or solution. They simply derive the optimal solution to any particular problem.

Most researchers (Wagner, 2007, Lucey, 2002, etc) posit that linear programming is an operation research technique. They maintain that it is among the most commercially successful applications of operations research with Wagner (2007) insisting that there is considerable evidence that it ranks highest in economic impact. He stresses that operations research adopts the view that managers can follow a fairly systematic process for solving problems. Therefore, it is possible to use a scientific approach to managerial decision-making. In his words, operations research technique is a scientific approach to problem-solving for executive management. Other areas of usage include airlines, agriculture, oil refining, education, energy planning, pollution control, transportation planning and schedule production planning, research and development, health care system and so on.

Emory and Niland (1968) listed the most difficult problems in using linear programming technique as the recognition of the necessary restrictions (constraints or row equations) and the possible 
alternatives (the column vectors) and the expression of these in linear equations. The difficulty is to construct, in mathematical form, an accurate definition of the problem. Knowledge of the problem, the details of company operations, the mathematics of linear programming technique and ordinary ingenuity all come into play in the application of linear programming model. Computer storage capacity is also an important issue because sometimes, it is surprising how swiftly practical problems require matrices of a size which task even the larger modern computers. Experiences in the application of linear programming problems show that collection of necessary cost and technical data is both time-consuming and expensive. The linear programming problem, note Emory and Niland (1968), sometimes costs more than the actual solutions because of the costly nature of getting the relevant data needed. For Turban (1993), there is the problem of risks and uncertainties regarding the behavior of customers, resources, and commodity prices \$uch that the management finds it difficult to choose the best decision among the alternative decision possibilities. He, therefore, recommends that managers must become more sophisticated, they must learn how to use new tools and techniques that are being developed in their field. These newly developed tools employ quantitative approach.

In pointing out limitations to its applicability, 'Kurtz (1992) notes that, often, very real organizational issues such as morale, consequences of strikes and internal power struggles are so difficult to quantify that they are ignored in the linear programming model used. Furthermore, considering the technicalities, managers who are conversant with its rigorous models resist its usage since they do not understand how it could be applied. But in his contributions, Taha (1992) lists other types of programming to include: integer, goal, quadratic, convex and stochastic. They differ, he maintains, in the kind of data they can handle and the kind of assumptions that are made. He finally illustrates how linear programming was applied to determine the feed mix to maintain a balanced ratio that includes calcium, protein, and fiber in the right proportion by the Ozark Poultry Farm.

Adam et al (1993) observe that optimization model aims at finding the best solution from a large or an infinite number of alternatives using a step-by-step improvement approach. Management seeks to find the best solution and an optimization algorithm identifies the steps for doing so.

\section{Theoretical Framework}

The General systems Theory (Buckey, 1967; Bertalanffy, 1968; Rapaport, 1985) was adopted as the theoretical framework of the study. In line with the General System Theory, a system can be defined as a set of interacting and interdependent units that last over time, operate within an established boundary, and satisfies the following conditions:

1) The behaviour of each unit in the system can affect the behavior of the entire system

2) The way the behaviour of each unit affects the behavior of the entire system depends on the behavior of at least another unit in the system (i.e. No unit has an independent effect on the system).

3) Every sub-unit of a system can affect its performance but none of them can have an independent effect on it. 
It can be deduced from the above facts that the total or overall performance of any system is not equal to the sum of the Independent performances of its unit or subunits, but is a function of their interactions. This is why any organization that wants to perform effectively must be holistic and synthetic by focusing and encouraging the interaction of the units and subunits, instead of focusing on the actions of the units or sub-units taken separately. Among the other characteristics of any system, that will help any manager to understand his organizations as a system is that for any system to qualify as one, it must strive to maintain internal equilibrium among its various subunits and its external environment. All these produce and involve managing changes in the internal and external environment of the system or the organization.

Elements of a system from Wikipedia, the free encyclopedia are; Input, output, process, control, feedback, boundary, interface and environment.

Input: input involves capturing and assembling elements that enter the system to be processed. The inputs are said to be fed to the systems in order to get them out: -ut. For example, in Steve shoe production center, the input consists of raw materials for shoe production, the human resources that make the labor hour input, finance etc. Output; refers to those elements that exist in the system due to the processing of the input A major objective of a system is to produce output that has value to its user. This is why the output in S.S.P.C. Enugu consists of pairs of shoes produced which are sold to the outside environment, the process is the element of a system that involves the actual transformation of input into output. It is the operational component of a system. This is where the production process takes place. The control element guides the system, it is the decision making subsystem that controls the pattern of activities governing input, processing, and output. It also keeps the system within the boundary set.

In boundary and interface, a system should be defined by its boundaries the unit that identifies its components, processes, and interrelationship when it interfaces with another system. The environment is the super system within which an organization operates. It is the source of external elements that impinge on the system. The interaction between systems and their environments are categorized in terms of relatively closed and open systems; An open system has many interfaces with its environment ie, a system that interacts freely with its environment, taking input and returning output to the outside. A closed system does not interact with the environment. Changes in the environment and adaptability are not issues for a closed system.

\section{Strategies to achieve Stated Objectives}

In this chapter, the discussion will focus on strategies to achieve the stated objectives, critique of the reviewed literature to identify possible gaps and critique on the theoretical framework would also be done.

1) In the first objective which sought to find out why Steve shoe production center, Enugu does not use linear programming model in determining its product mix; to achieve this, the researchers would have done a detailed interview by asking relevant questions directed to the owner of S.S.P.C Enugu and other key personnel. This would have enabled the researcher to have a detailed understanding of the source of the problem, and this would 
have enhanced the researcher's capability to develop a working model that would represent the true situation of S.S.P.C Enugu with a minimal error.

2) The second objective which sought to practically develop a linear programming working model for the production process of SSPC Enugu would have been achieved by the researchers by seeking relevant data from the owner of the production centre, which comprise costs of direct materials, for each product, direct wages for each product and for each of the three departments, known as cutting department, making department and finishing department.

The researcher also would have obtained relevant data for each department respectively regarding a number of employees, hours per employee per week and wage rate per hour. Thus, these would have enabled the researcher to calculate the hours per product required in each department, after which the selling price per product and the respective variable costs per product would have been determined to facilitate the computation of the contribution margin per unit.

The relevant data gathered by the researcher would have facilitated the development of linear programming model of this replica.

Maximize $\mathrm{P}=\mathrm{Ux}_{1}+\mathrm{L}_{2} \mathrm{X}_{2}$

Subject to: $\mathrm{C}_{12} \mathrm{X}_{2},<\mathrm{C}_{22} \mathrm{X}_{2}<\mathrm{B}_{2} \mathrm{C}_{32} \mathrm{X}_{2}<\mathrm{B}_{3} \mathrm{k}$ ! $>0, \mathrm{X}_{2}>0$

Where $\mathrm{p}=$ Total profit contribution of the two products of steve shoe production centre Enugu.

li $-2=$ profit contribution coefficient $x i-2=$ The set of unknown that would determine the products to be produced by SSPC Enugu.

$\mathrm{C}=$ The numerical values that express the per unit usage of the right-hand side, b! - 3: The resource values that are to be utilized.

Also, the researcher would have focused on the labor hours needed for the production per week, being the resource values to be utilized. Thus other factors would be held constant.

3) The third objective which sought to demonstrate how the developed linear programming working model can assist SSPC Enugu to optimize its resources for effective output decisions would have been achieved by working out the optimal result of the model using the simplex method which is an arithmetic step by step procedure and the optimal value of the objective function would have maximized contribution to profit. Also, the researchers would have used the optimal simplex tableau to reveal the shadow prices which measure the marginal or incremental economic values of resources to an organization. These shadow prices would be used to further expose the workability of the model as it would reveal the labor hours that are fully utilized and the un-used labor hours.

The researcher would have subjected the linear programming model to sensitivity analysis. Thus, this sensitivity analysis would have been used as a means of demonstrating to SSPC Enugu, the advantages of the impact of changes in system constraint for the respective departments. The researcher also would have gone further by demonstrating how changes in system constraints (labor hour) would have guided the management of SSPC Enugu on making an informed decision regarding resource utilization in terms of overtime options and utilization. Also, the researchers 
would have computed the impact of changes in the objective function coefficient for each decision variable. Thus, this would have guided the management of SSPC Enugu on their decisions with regards to the fluctuations of the objective function coefficients. To ensure that objective three would be more meaningful, the researcher would have guided the management of SSPC Enugu appropriately in the implementation of the model in possible ways that would be cost-effective.

\section{Critique of the Reviewed Literature}

The empirical and theoretical reviews so far,' have explained the application of linear programming models in different areas among which are textile firms, maintenance and manpower planning, dormitory development etc. Within the knowledge of the researchers, the study of optimization of resources with the aid of linear programming model in shoe manufacturing firms appears to have been under-researched. However, irrespective of the areas in which the studies of linear programming have been conducted, the overall underlying assumptions of linear programming remain the same. Kurtz (1992) in the literature reviewed, is of the opinion that considering the technicalities in linear programming models, managers who are not conversant with its rigorous models, resist its usage since they do not understand how it could be applied; this is part of the problems the researchers intend to solve by showing a practical demonstration of how workable the model would be; and to convince the management of SSPC Enugu on the possibility of usage of the linear programming model.

\section{Critique of the Theoretical Framework}

Systems model is generally a basic principle in engineering and in social sciences; the system is the representation of the entities under concern. Hence, inclusion to or exclusion from system context is dependent on the intention of the modeler. No model of a system will include all features of the real system of concern, and no model of a system must include all entities belonging to a real system of concern. Managers should be familiar with the meanings and characteristics of the open system and closed system. According to the General systems theory, closed systems have generally impermeable boundaries, so they cannot exchange matter, energy or information with their environments. Open systems on the other hand exchange inputs and outputs through boundaries that are permeable. From the above analysis, the researcher can state that every organization should strive to operate an open system all the time. However, real life experiences show that it is not simple.

While it is much better for managers to recommend and encourage or advice that their organizations operate the open system, most of the time, an organization should be able to identify or recognize those situations when it is necessary to operate as a closed system for example in handling official secrets or confidential matters. Meanwhile, business systems cannot be completely closed or totally open. So they are either relatively open or relatively closed. In the context of the above, linear programming model would perform very effective when there is a balance between operating a closed system and open system. 


\section{Conclusion}

The study has shown that linear programming model can be applicable in Steve Shoe Production center, Enugu. The researcher, through observation, noted that decision making regarding the quantity of shoes to be produced was based on trial and error method which yielded sub-optimal results. The researcher, in an attempt to fill this gap, has demonstrated practical means of developing a working linear programming model to find solution to the problem of sub-optimal results often realized by SSPC Enugu. Also, the literature reviews in this work have - further affirmed that linear programming model is workable.

\section{Recommendations}

Based on findings from the study, the following recommendations were made.

1) Operations research practitioners should consider the use of linear programming model in small-scale manufacturing firms as a virgin area to explore their services in a more effective manner and this could be one of the means of reducing business failure in Nigeria and will be a source of extra income to Operational Research practitioners

2) From the research's personal observations, in the course of this research study, shoemakers and other small-scale manufacturers are not literate enough in the area of operations research. Thus, the small-scale manufacturers should rely on outside consultants to bring these services to their doorstep at moderate cost.

3) Emphasis should be on practical demonstration of linear programming model while teaching operations research in Nigerian universities. This is because; the practical demonstrations would equip the future entrepreneurs better than before to face decision making challenges more competently.

\section{References}

[1] Adeyemo, J, \& F. Otiero, (2009). Optimizing planting areas using differential evolution and linear programming. International Journal of Physical Sciences, (4): 212-220.

[2] Agbadudu.B. A, (1996). Elementary Operations Research, Benin: A.B press.

[3] Agbadudu, A. B. (2006). Operations Research, Mathematics and Social Sciences: The Link, Inaugural Lecture Series 86 of the University of Benin, Uniben Press.

[4] Akingbade, F., Luck, M. \& Ratal, N. (1991). Concepts and Applications of Operational Research in Development Management, Lagos: Centre for Management Development.

[5] Akiniyi, J. A., (2008). Allocating available resources with the aid of linear programming: a roadmap to economic recovery, Multidisciplinary Journal of Research development, 10(2), 113139.

[6] Anderson, D. R, Sweeney, D. J. \& Williams, T. A. (1997). An Introduction to Management Sciences, New York: West Publishing Company.

[7] Andre B. et al, (2003). Linear Programming: A Mathematical Tool for Analyzing and Optimizing Children's Diets during the Complementary Feeding Period, Journal of Pediatric Gastroenterology and Nutrition, (36) 12-22.

[8] Azar, A. (1999). Operations Research I. Payam-e Noor Publications.

[9] Benedict, E. \& Uzochukwu, A. (2012). Optimizing profit with the Linear Programming Model; Interdisciplinary Journal of Research in business. 2(2), 37 - 49. 
[10] Buckey W. (1967). Sociology and Modern Systems, Eaglewood - Cliffs, New Jersey: Prentice Hall Inc.

[11] Charles, Cooper \& Henderson, (1963), An Introduction to Linear Programming, New York; John Willy,

[12] Cui A. et al, (2006). Linear Programming Detection and Decoding for MIMO System, IEEE Commun. Lett, (9) 5, 423-425.

[13] Dantizig, G., (1993). Computational Algorithm of the Revised Simplex Methods, RAND Memorandum RM-1266.

[14] Dhanalashm R. et al, (2009). Tamil POS tagging using linear programming. International Journal of Recent Trends in Engineering, 3(2), 166-169.

[15] Dwivedi, D., (2008), Managerial Economics, VIKAS Publishing House PVT Limited, New Delhi Outline Series, New York; McGraw-Hall Inc.

[16] Guilani-Nia, Sh. (2005). Advanced Research in Operations (Applied Concepts).

[17] Hareem B \& A. Aderoba, (2008). Linear Programming based Effective Maintenance and Manpower Planning Strategy, International Journal of the Computer, the Internet, and Management, 1(6) 26-34.

[18] Henderson, J, \& Quandt, R. (2003). Microeconomic Theory: A Mathematical Approach, New Delhi; McGaw-Hill Book Co., Tata.

[19] Hillier, F, \& Lieberman, G. (2001). Introduction to Operations Research, New York; McGaw-Hill Book Co.

[20] Izaz U. K. et al (2011). Optimal Production Planning for ICI Pakistan using Linear Programming and Sensitivity analysis. International Journal of business and social science (2) 23 special issues December 2011.

[21] Koji, T \& R. Gunner, (2002). Image reconstruction by Linear Programming. Max Planck Germany; Institute for Biological Cybernetics, Spemannstr, 38, 72076,

[22] Koutsoyinnis, A. (1987). Modern Microeconomics. English Language Book Society, Macmillan Press Ltd.

[23] Kurtz, D et al, (1992). Principles of Management USA; McGraw-Hill Inc. Lucey, T. (2002). Quantitative Techniques. London: Thompson Learning.

[24] Mehdipoor, E. \& Sadr-ol-ashraafi, S. M. \& Karbaasi, A. (2006) A Comparison of Canonical Linear Programming Techniques, Meaty Chicken' Feed Framing With Linear Programming Models, Scientific-Research Magazine of Agriculture, 12th year, issue no. 3

[25] Mudiaga Aiden- J. W. (2009). Problems and Prospects of establishing small-scale enterprises in Nigeria] A Project Research Deportment of-business administration Caritas University Enugu.

[26] Murugan, N \& S. Manivel, (2009), Profit Planning of an NGO run Enterprises using Linear Programming Approach, International Research Journal of Finance and Economics, (23), 443-454

[27] Nedim F. et al, (2002). A sample of Determination of Product combination with Linear Programming in Risk Environment, European Journal of Economics, Finance and Administrative Sciences, 5(3), 30-45.

[28] Orlin, J. B (2007). Optimization Methods in Management translated by Mohammad-

[29] Reza Hamidizadeh Rapaport A. (1985) General Systems Theory: Essential concepts and applications, Tunbridge Wells: Abacus Publishers UK.

[30] Rrnory, W, \& P. Niland, (1998). Making Management Decisions, New Delhi Gupta Oxford \& IBH,

[31] Susilawati B. et al, (2002). Application of Linear Programming for Dormitory Development Plan at Petra Christian University. http.//puslit.petra.ac.id/ journals/civil, Indonesia

[32] Teha, H. (2008). Operations Research: An Introduction, New Delhi 110001 PHI Learning Private Limited.

[33] Turban, I \& Meredith, T. (1991). Principles of Management Science, Prentice Hall, and India Private Ltd. 
[34] Turban, 1, (1993). Decision Support and Expert Systems: Management Support Systems. New York; Macmillan Publishing Company.

[35] Wagner, H.; (2007), Principles of Operations Research with Application to Managerial Decision, New Delhi; Prince-Hall of India Private Limited.

[36] Yahya F. A. (2004). "The use of linear programming the design of antenna pattern with prescribed nulls and other constraints", compel: The International Journal for Computation and Mathematics in Electrical and Electronic Engineering, 3(4), 201 - 215

*Corresponding author.

E-mail address: nosagosagie4rea@gmail.com/ichememonday@ gmail.com 